\title{
Hospital Information Integration Based on Integration Platform
}

\author{
Jinguo Wang ${ }^{1}$ and $\mathrm{Na}$ Wang ${ }^{2, a, *}$ \\ ${ }^{1}$ Department of Urology, First Hospital of Jilin University, Changchun, China \\ ${ }^{2}$ Department of Anesthesiology, First Hospital of Jilin University, Changchun, China \\ ${ }^{*}$ Corresponding author: Na Wang
}

\begin{abstract}
This paper analyzes the current situation of hospital informatization, and puts forward a new solution to realize the integration of hospital information system to make up the defects of the traditional integration scheme in the current hospital informatization construction. Medical information integration and data sharing are realized by building a unified hospital information integration platform based on HL7 standards, SOA architecture and ESB technology. Each independent medical information subsystem is closely linked through the hospital information integration platform. On the base of the open architecture, the integration platform has strong scalability and supports the connection of customized adapters and the application of complex heterogeneous systems, so as to realize the data sharing and information collaboration among various hospital systems.
\end{abstract}

\section{Introduction}

In recent years, with the process of medical reform, medical and health informatization has become an important measure to help conduct medical reform and improve health management and service efficiency. According to the requirements of overall design and stepby-step implementation, local health authorities have simultaneously promoted the informatization construction of public health, medical treatment and health records, and achieved certain results [1].

However, there are still problems in the construction of medical informatization, such as the lack of standard guidance and the inability to unify modules from the perspective of the practical application of grassroots medical institutions, due to the different levels and needs of hospitals. Based on the digital construction of basic medical institutions and public health institutions, this paper discusses some opinions on the construction of unified medical and health informatization platform [2].

\section{Defects in the traditional integration}

From point-to-point integration to middleware-based integration, they continue to grow in scalability and availability and integration capabilities, but either way is a specific solution [3]. Their technical approach is specific to application systems and software vendors, using proprietary technologies rather than open standards that prevent hospital application integration systems implemented by different integration technologies from operating with each other [4]. In order to share the data of each department with each other, each system has to

\footnotetext{
a Corresponding author: wangna080613@163.com
}

complete numerous interfaces with each other, which will make it difficult to realize the whole data sharing. At the same time, the authority of query is limited, and the management of medical records cannot be unified. This is also a reflection of the low level of hospital system integration. The sharing of business data only meets the local needs of a single point, and the whole system is not integrated as a whole [4].

\section{Measures of the development of information integration}

\subsection{Strengthening innovation consciousness}

As Chinese situation of electronic information engineering market competition is increasingly severe, engineering companies need to constantly improve the ability to innovate, develop more innovative products in order to make the electronic information industry healthy development [5]. In order to meet the needs of the domestic market and the international market, the electronic information industry needs to be more intelligent and digital, and related enterprises should strengthen the research and development of electronic information technology, and at the same time conduct comprehensive cooperation and exchanges, so that China's electronic information engineering applications in various fields [6]. Electronic information products should be optimized and innovated to meet the current domestic market demand with their own innovation, so that China's electronic information technology can eventually compete with developed countries, which is conducive to the modernization of Chinese electronic information 
technology innovation and development.

\subsection{Establishing the standard in the field of electronic information engineering}

At present, improving and perfecting the standard system is necessary to give full play to the government and the relevant departments in the field of electronic information engineering in China [7]. It can speed up the legislative process and increased from aspects such as policy support, actively encourage technical innovation activities in electronic information engineering, expand the financing channels, in the field of electronic information engineering. Abundant financing models provide strong impetus for development of electronic information industry. Relevant departments should also strengthen supervision and management of electronic information engineering.

At the same time, it is necessary to strengthen the protection of intellectual property rights, guide scientific and technological personnel in the field of electronic information engineering to improve their awareness of intellectual property protection. It improves the intellectual property protection system, safeguard the legitimate rights and interests of scientific and technological personnel, and stimulate and mobilize their enthusiasm and creativity in scientific research and technological innovation [8].

\subsection{Paying attention to talent training}

Talent is an important factor in the development of science and technology, so we should try to optimize the talent team in this aspect in China. Education career is now in full swing, electronic information engineering is widely welcomed, but the quality of its teaching is worrying. In view of this situation, colleges and universities should actively change the education concept and enrich the teaching model [9]. In addition, more practical opportunities should be given to students, and the cooperation between hospitals and enterprises can be strengthened.

\subsection{Combination of resources}

Many electronic information engineering started late, coupled with insufficient funds, technology research and development, product research and development caused great constraints. Some enterprises start early in information technology, have sufficient funds and more talents, but they are small in scale. Through the combination of these two types of enterprises, it can not only solve the capital problem, but also promote the utilization efficiency of talents, reduce the unemployment rate, reduce the risk of enterprise bankruptcy, and promote the growth of enterprise scale [10]. In addition, on the basis of internal cooperation, it is also necessary to strengthen external development, enhance technology and scale, and continuously enhance the competitiveness of enterprises in the international market, so as to make greater contributions to the social and economic development of China [11].

\section{Application examples}

Scenario description: HMIS of the hospital is integrated with the newly built RIS of the hospital. HMIS was built many years ago. The system USES PB8.0 to develop the front end, and sybase database is used in the background. RIS is a newly introduced foreign product, and the system only supports HL7 interface. The integration must realize that the inspection application form issued by doctors in HMIS can be transmitted to RIS, and the inspection report form generated by RIS can be returned to HMIS for doctors to review and electronic medical record introduction [12]. On the basis of data integration, and supported by the hospital information platform, the work of patient examination and the transfer of data information between positions set up by the hospital are completed, which not only ensures that data is not repeatedly input, but also makes it convenient to query the status of patients in the process of examination. So that each work station can easily know the work situation of the previous post and the completion status of each patient, thus forming a complete workflow mechanism [13]. Process integration is the basis of image preallocation and automatic routing.

\section{Conclusion}

Aiming at the defects of the traditional integration scheme, this paper proposes to build a unified application integration platform to realize the integration of information systems within and between hospitals. Through the hospital information platform and referring to the IHE technical framework and architecture, loose coupling integration is carried out to achieve the integration of heterogeneous system data within the hospital. The original can only depend on the specific information system respectively in patients with related data, such as attendance record, the doctor's advice, fee itemizations, inspection report, the hospital medical record, etc., effectively unified to the corresponding patient records, the original is given priority to with each department or system of patient information organization into a real way of taking patients as the center of the organization, all the data are real-time classification to patients with specific name. This is a substantial breakthrough in the field of domestic informatization and a concrete embodiment of patient-centered management concept in hospital operation practice. Therefore, building such an integrated platform is the guarantee of the sustainable development of hospital information system.

\section{References}

1. Sagi Filin, Norbert Pfeifer. Segmentation of airborne laser scanning data using a slope adaptive neighborhood. ISPRS Journal of Photogrammetry and Remote Sensing, 2005 (2).

2. Marlene Asselin. Improving literacy education 
through professional study: the leadership role of the teacher-librarian. Teacher Librarian, 2003.

3. Luigi T. De Luca, Propulsion physics EDP Sciences, Les Ulis, 2009.

4. Robin Poston, Severin Grabski. Financial impacts of enterprise resource planning implementations. International Journal of Accounting Information Systems, 2001 (4).

5. M. Mazhar Rathore, Anand Paul, Awais Ahmad, Suengmin Rho. Urban planning and building smart cities based on the internet of things using big data analytics. Computer Networks, 2015.

6. Yongha Park, Morton E. O'Kelly. Fuel burn rates of commercial passenger aircraft: variations by seat configuration and stage distance. Journal of Transport Geography, 2014.

7. Samuel Nunn, Joseph B. Rubleske. Webbed cities and development of the national information highway: The creation of worldwide web sites by U.S. city governments. Journal of Urban Technology, 1997 (1).

8. Markus Granlund. Moderate impact of ERPS on management accounting: a lag or permanent outcome?. Management Accounting Research, 2002 (3).

9. Shangyi Zhou, Juncheng Dai, Jianhua Bu. City size distributions in China 1949 to 2010 and the impacts of government policies. Cities, 2013.

10. James E. Prieger. The broadband digital divide and the economic benefits of mobile broadband for rural areas. Telecommunications Policy, 2013 (6-7).

11. Roberto Trasarti, Ana-Maria Olteanu-Raimond, Mirco Nanni, Thomas Couronné, Barbara Furletti, Fosca Giannotti, Zbigniew Smoreda, Cezary Ziemlicki. Discovering urban and country dynamics from mobile phone data with spatial correlation patterns. Telecommunications Policy, 2013.

12. Saeed Sarencheh, Bahram Sadeghi Bigham. An applicable master plan to develop city's information technology infrastructure. Procedia Computer Science, 2011.

13. Milan K. Shrestha, Abigail M. York, Christopher G. Boone, Sainan Zhang. Land fragmentation due to rapid urbanization in the Phoenix Metropolitan Area: Analyzing the spatiotemporal patterns and drivers. Applied Geography, 2011 (2). 